\title{
Physical Inactivity, Non-Communicable Diseases and National Fitness Plan of China for Physical Activity
}

\author{
Rashid Menhas, (D) \\ Jianhui Dai, ${ }^{2}$ \\ Muhammad Azeem Ashraf, (iD ${ }^{3}$ \\ Sohail M Noman, ${ }^{4}$ \\ Sumaira Khurshid, ${ }^{5}$ \\ Sajid Mahmood, ${ }^{6}$ Yu Weng, (iD ${ }^{2}$ \\ Rizwan Ahmad Laar, (iD ${ }^{7}$ \\ Xuehui Sang, (iD ${ }^{2}$ \\ Muhammad Kamran, ${ }^{8}$ \\ Babar Shahzad, ${ }^{9}$ Waseem lqbal ${ }^{9}$ \\ 'Research Center of Sports Social Sciences, \\ School of Physical Education and Sports, \\ Soochow University, Suzhou, 215006 \\ Jiangsu Province, People's Republic of China; \\ ${ }^{2}$ School of Physical Education and Sports, \\ Soochow University, Suzhou, 2I 5006, \\ Jiangsu Province, People's Republic of China; \\ ${ }^{3}$ Research Institute of Educational Science, \\ Hunan University, Changsha, 4I0082, \\ People's Republic of China; ${ }^{4}$ Department of \\ Cell Biology and Genetics, Shantou \\ University Medical College, Shantou, \\ Guangdong, 5 1504I, People's Republic of \\ China; ${ }^{5}$ School of Education and Science, \\ Neijiang Normal University, Neijiang, \\ Sichuan Province, People's Republic of China, \\ 64III2; ${ }^{6}$ Department of Zoology, Hazara \\ University, Mansehra, 21 I20, Pakistan; \\ ${ }^{7}$ School of Sports Science and Physical \\ Education, Nanjing Normal University, \\ Nanjing, 210023, People's Republic of China; \\ ${ }^{8}$ NRSP Microfinance Bank Shorkot City \\ Branch, Shorkot, 35050, Punjab, Pakistan;

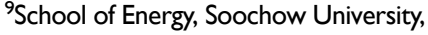 \\ Suzhou, 215006, Jiangsu Province, People's \\ Republic of China
}

Correspondence: Muhammad Azeem Ashraf

Research Institute of Educational Science, Hunan University, Changsha, 4I0082, People's Republic of China

Email azeem20037@gmail.com
Background: China has the world's largest population, going under health transition due to industrialization, urbanization, and a sedentary lifestyle. About $82 \%$ of China's disease burden is due to the prevalence of non-communicable diseases (NCDs). Physical activity (active travel) is the best preventive measure against NCDs. The Chinese government has introduced several steps to improve national fitness and overcome NCDs among the aging population. Exercise and sports play a vital role in promoting physical activity and helpful in accomplishing the national fitness level for Healthy China under the national fitness plan (NFP).

Objective: The current study aimed to explore the role of national fitness plan (NFP) in promoting physical activity and health well-being preventing NCDs under built environment intervention.

Methods: The study was exploratory, and the mixed-method approach was used to analyze the primary and secondary data. Quantitative content analysis was used to analyze the collected data. A purposive sampling technique was used to collect the primary data from those individuals rich in knowledge about the National Fitness Plan (NFP) of China and its role in promoting physical activity for physical fitness.

Results: The majority of the participants $(32.0 \%)$ said that the national fitness plan helps promote sports environment and health. About $28.0 \%$ reported that NFP helps promote cycling and walk environments for physical activity and health promotion and preventing non-communicable diseases (NCDs).

Conclusion: Participation in physical exercise and sports is the preferred approach to prevent different diseases. In the context of rising active living among the Chinese people, the facilities such as built environment and green parks under the national fitness plan (NFP) for sports play a crucial role in the mitigation of NCDs.

Keywords: non-communicable diseases, physical activity, built environment, sports, national fitness

\section{Introduction}

Physical inactivity is a major contributing factor in global mortality. ${ }^{1}$ It is estimated across the world that physical inactivity triggered about $20 \%$ of the disease burden from colon and breast cancers, about $6 \%$ coronary heart disease, and about $7 \%$ of type 2 diabetes. $^{2}$ An inactive lifestyle is a significant root of millions of preterm deaths worldwide each year and results from sedentary behavior. ${ }^{3}$ Poor nutrition and physical inactivity are the main factors of death. ${ }^{4}$ Disuse syndrome is the so- 
called result of inactive living. The prevalence of NCDs (depression, obesity, premature aging, musculoskeletal fragility, and cardiovascular vulnerability) is also the negative consequence of physical inactivity. ${ }^{5}$ In high-income countries, the inactive citizens' ratio is growing (32\% in 2001 to $37 \%$ in 2016), although it is stable at $16 \%$ in lowincome countries. Men in eastern and southeast Asia are found to be more active than women. ${ }^{2}$ Physical inactivity is the fourth risk factor for global mortality, further impacting the prevalence of NCDs. Professional health bodies and the WHO have developed policies for the promotion of physical activity. The available evidence shows that physical activity intervention helps treat NCDs and improves the quality of life. ${ }^{6}$

\section{Physical Inactivity Scenario of China}

Physical inactivity is the 3rd leading cause of death. NCDs due to physical inactivity are the significant cause of increasing global mortality, and it can increase the death rate from about $20 \%$ to $30 \%{ }^{7}$ Rapid urbanization and modernization in China are correlated with increasing sedentary activity and lifestyles. Between 1991 and 2006, the physical activity level decreased at an unprecedented rate. ${ }^{8}$ The highest percentage of physical activity decline has been found in China compared to India, Brazil, the UK, and the US. ${ }^{9}$ Environmental and societal changes have effects on the physical activity level of the population. In modern society, urbanization, increased use of motorized transport, and mechanization are the main leading factors of change in physical activity trends at the global level. Technological advancement impacts the levels of physical activity because it reduces a lot of physical labor. Sedentary leisure time has become attractive due to computers, cell phones, and electronic entertainment. In this paradigm, low-income countries are physically more active due to walking, cycling, and manual jobs. High-income countries are physically less active due to sedentary leisure recreations, which result from new technologies. Moreover, it is also estimated that middle and low-income countries will also reduce the physical activity level due to technological transition. ${ }^{10}$ According to the recommended levels of physical activity, about $80 \%$ of adolescents (13-15 years old) are not achieving the target level across the globe. ${ }^{11}$ In Chinese society, especially in cities, children depend on their parents for daily transportation and the growing trend of vehicle ownership, reducing the Chinese population's physical activity level. ${ }^{12}$ National Physical Fitness and Health Surveillance 2010 of
China indicated that about $77.3 \%$ of school-going adolescents failed to achieve the recommended level of physical activity. ${ }^{13}$

\section{Non-Communicable Diseases Scenario of China}

China is an emerging world economic power and going through rapid modernization, urbanization, and economic growth. As rapid economic growth is happening in China, life expectancy is also increasing. In the modern and urbanized Chinese society, lack of physical activity, obesity, tobacco use, excessive alcohol use, sugar, and saturated fats, and excess salt has prevailed and further contributed to NCDs' prevalence. ${ }^{14}$ The NCDs burden is expected to increase in both sexes from 2010 to 2030 in China among the aging population. ${ }^{15}$ The development of NCDs among the aging population is the result of behavioral factors. The behavioral risk factors (physical inactivity, tobacco use, unhealthy diet, obesity and overweight, high blood pressure, dyslipidemia, and raising blood glucose) are essential biological factors for the prevalence of NCDs in China. According to the WHO, about 580 million Chinese were had one modifiable NCD risk factor in 2010. The biggest health threat is NCDs in China, and about $80 \%$ (10.3 million) annual deaths are happening due to NCDs. ${ }^{16}$ According to the WHO, about $68.6 \%$ of the disease burden is NCDs. ${ }^{17} \mathrm{CVD}$ is the leading cause of death. In other diseases, cancer is about $4.1 \%$, about $2.7 \%$ chronic respiratory diseases (CRD), about $12.8 \%$, endocrine, nutritional and metabolic disease about $2.3 \%$, and other diseases about $27.1 \%$. According to the given statistics below, the burden of NCDs will be doubled among the Chinese people age group of 40 during the next ten years. The NCDs which are going to be increased in the next ten years are heart-related diseases, chronic obstructive pulmonary diseases (COPDs), myocardial infarction, lung cancer, and diabetes mellitus (DM) ${ }^{18}$ Other NCDs' prevalence rate was higher in rural populations than the urban population, such as type 2 diabetes about $304.2 \%$ (from $2.4 \%$ to $9.7 \%$ ) and hypercholesterolemia about $366.7 \%$ (from $1.8 \%$ to $8.4 \%$ ) rate increased among China's rural people. In urban China, it increased about $197.6 \%$ (from $4.1 \%$ to $12.2 \%$ ) and $173.3 \%$ (from $4.5 \%$ to $12.3 \%$ ). ${ }^{19}$

\section{National Fitness Plan (NFP)}

China adopted the physical health law in 1995, and in the same year, the State Council implemented a physical 
fitness program across the country. A proposal to improve the Chinese youth's physique through sports and accelerate the sports industry's growth was published in 2007 and 2014. By the end of 2005, the State Physical Culture Administration had established around 6000 national physical fitness facilities across rural areas. ${ }^{20}$ To address physical inactivity and NCDs health issues, a comprehensive plan named "National Fitness Plan (NFP)" introduced by the Chinese government in two phases (2011-2015) and (2016-2020). A substantial increase in the number of people engaged in physical activity is expected to occur within this initiative's context by $2020 .^{21}$ In promoting and meeting the Sustainable Development Goals of the United Nations, physical activity also plays a significant role. In response to health-related SDGs, the National Fitness Plan (2016-2020) and Healthy China 2030 were planned by the Chinese State Council. ${ }^{22}$ The State Council has also made appropriate changes to the national fitness campaigns after the outbreak of COVID-19 in late 2019 and mandated newly developed communities to provide recreational facilities under regulations.

\section{Statement of the Study}

According to the WHO, physical inactivity is the fourth risk factor for global mortality, further impacting NCDs' prevalence. Professional health bodies and the WHO have developed policies to promote physical exercise and sports for active living. The existing evidence indicates that physical training and sports intervention are valuable in treating NCDs and enhancing life quality. Sports and physical activity lead to a healthy society in many ways. Physical exercise enables a balanced lifestyle in the community through various other variables, such as the planned environment for physical exercise and sports. ${ }^{23}$ Changes and construction of a sustainable built environment have a significant impact on sports and physical activity participation. The current study was designed to explore the role of national fitness plan in promoting physical activity and health well-being preventing NCDs under the built environment intervention. The National Fitness Plan (NFP) for the promotion of sports and physical activity among the Chinese population was implemented by the Chinese government to address the risk of NCDs. The National Fitness Plan (NFP) plays a critical role in encouraging exercise and sports among older adults and helps to achieve the national sustainable level of fitness by preventing NCDs. The environment in which physical activity and sports are taking place has a substantial effect on health. In developing countries, physical activity and sports have a significant contribution to the well-being of people. Sports, physical activity, and various kinds of exercise have long been used to treat NCDs.

\section{Materials and Methods}

The current study used quantitative content analysis under the mixed-method approach in an open-ended form and conducted in Suzhou city, Jiangsu Province, People's Republic of China. The content analysis can be used in both qualitative and quantitative conditions according to the study nature and available resources. ${ }^{24}$ The quantitative content analysis was used to explore the role of the national fitness plan in the promotion of physical activity and health well-being. The researchers employed a purposive sampling technique to collect the primary data from those individuals who are rich in knowledge about the National Fitness Plan (NFP) of China and its role in promoting physical activity for physical fitness.

\section{Study Design}

The study was exploratory, and the mixed-method research $(\mathrm{MMR})^{25}$ approach was used to analyze the primary and secondary data. The secondary source is General Administration of Sports of China surveys and the 6th National Sports Venues Census of China. The secondary data was both in qualitative and quantitative form. Only those secondary data were included in the study, which the government reported. Quantitative content analysis is one of the best exploratory research approaches to evaluate and understand the open-ended qualitative data form in its context. $^{26}$ It is a systematic and objective way of phenomenon description and quantification. ${ }^{27}$ For useful content analysis, a prerequisite is that knowledge can be reduced to explain the research phenomenon. ${ }^{28}$ The phase of abstraction is the stage during which concepts are generated in quantitative content analysis. A few features of the method may generally be easily explained. Still, it also relies partly on the researcher's intuition or analytical behavior, which can be very hard to explain to others. ${ }^{29}$ The main steps of the quantitative content analysis performed in the study were designing, utilizing, sampling, recording, reducing, inferring and narrating.

\section{Participants}

In qualitative research, purposive sampling is widely used. Only those key informants are selected who are rich in 
knowledge about the point of interest ${ }^{30}$ to use limited available resources.

Eligibility for the Participation in the Interview Following is the eligibility criteria to participate in the study interview;

(I) Know the national fitness plan (NFP) of China

(II) Know the importance of sports and physical activity for health well-being

(III) Know the importance of the built environment for sports and physical activity

(IV) Participate in physical activity for healthwellbeing

A total of 25 participants were selected through purposive sampling techniques in which $11(44.0 \%)$ men and 14 (56.0\%) were women. The demographic information of the participants is given below in the table.

\section{Socio-Economic Features of the Interview Participants}

Table 1 shows the socio-economic features of the interview participants. The gender distribution shows that most participants $(56.0 \%)$ were female, and about $(44.0 \%)$ were male. The age statistics show that the majority of the participants, about (44.0\%) belonged to the age group of (19-35 years) and about (36.0\%) were belong to the (19-35 years old) while only about $(20.0 \%)$ were belong to the $(56+$ years). In ethnicity, most of the participants $(52.0 \%)$ belong to the Han ethnicity group, and about $(28.0 \%)$ belong to the national minorities group. In comparison, only almost (20.0\%) belong to the other groups. The educational background shows that the majority of the participants about (44.0\%) were college graduate, about $(20.0 \%)$ were university graduate, and about (12.0\%) had less than high school level education while only about (24.0\%) had another type of education such as technical and vocational. The occupational paradigm of the participants shows that the majority about $(52.0 \%)$ were selfemployed, about (36.0\%) were students, and about $(8.0 \%)$ government employees, while only about $(1.0 \%)$ belong to the other group. Marital status statistics show that the majority of the participants about $(60.0 \%)$ were married, about (16.0\%) single and about $(12.0 \%)$ divorced, while about $(8.0 \%)$ widowed.
Table I Demographic Information of the Study Participants $(\mathrm{N}=25)$

\begin{tabular}{|c|c|c|}
\hline Variable & Categories & Frequency/Percentage \\
\hline \multirow[t]{2}{*}{ Gender } & Male & II (44.0\%) \\
\hline & Female & $14(56.0 \%)$ \\
\hline \multirow[t]{3}{*}{ Age } & $19-35$ & $9(36.0 \%)$ \\
\hline & $36-55$ & II (44.0\%) \\
\hline & $56+$ & $5(20.0 \%)$ \\
\hline \multirow[t]{3}{*}{ Ethnicity } & Han & $13(52.0 \%)$ \\
\hline & National Minority & $7(28.0 \%)$ \\
\hline & Others & $5(20.0 \%)$ \\
\hline \multirow[t]{4}{*}{ Education } & Less than high school & $3(12.0 \%)$ \\
\hline & College Graduate & II (44.0\%) \\
\hline & University Graduate & $5(20.0 \%)$ \\
\hline & Others & $6(24.0 \%)$ \\
\hline \multirow[t]{4}{*}{ Occupation } & Student & $9(36.0)$ \\
\hline & Government Employee & $2(8.0 \%)$ \\
\hline & Self-employed & $13(52.0 \%)$ \\
\hline & Others & I (4.0\%) \\
\hline \multirow[t]{4}{*}{ Marital Status } & Single & $4(16.0 \%)$ \\
\hline & Married & $15(60.0 \%)$ \\
\hline & Divorced & $3(12.0 \%)$ \\
\hline & Widowed & $2(8.0 \%)$ \\
\hline
\end{tabular}

\section{The Procedure}

Data Collection Tool: An interview guide was used as a data collection tool in the current study. The nature of the interview guide was qualitatively based upon openended questions according to the study's objectives. The focus of the interview questions was knowledge about the national fitness plan, the importance of sports for physical activity and health-wellbeing, the importance of the built environment for sports and physical activity and participation in physical activity. There are several methods available to contribute to the formation of interview guides. Patton's ${ }^{31}$ method is adopted in the current study to design the interview guide.

Pre-testing of Interview Guide: A pre-testing was conducted of the interview guide on six key informants in the study area. Some questions were re-designed after the pre- 
testing, and some overlapping questions were removed from the final interview guide.

Final in-depth Interview: Informed consent had been taken from the study participants after provided the study purpose information. The semi-structured in-depth interview was conducted face to face, and participant's responses were recorded in the written form. More than 45 minutes were spent for each participant's face-to-face in-depth interview.

Data Quality Check: The member checking method was used to ensure the quality of the collected data. Debriefing or member checking is a method of returning and confirming the analytical results of the interview with the study participants. ${ }^{32}$ This method also allows a new researcher to assess the data's quality in the best way.

\section{Secondary Data}

Surveys conducted by the General Administration of Sports of China and the 6th National Sports Venues Census of China were included as secondary data to achieve the study objective. Following are the sources of secondary data.

(I) General Administration of Sport of China survey $1997^{33}$

(II) General Administration of Sport of China survey $2001^{34}$

(III) General Administration of Sport of China survey $2007^{35}$

(IV) General Administration of Sport of China survey $2015^{36}$

(V) The 6th National Sports Venues Census of China $^{37}$

The Chinese government introduced several laws to promote sport and physical culture for active and healthy living. The governmental laws were initiated to promote sport and physical activity across China. The Chinese government provided sport and physical exercise facilities at the community level to tackle the physical inactivity and NCDs problem among the Chinese residents. After implementing the policies, the General Administration of Sports of China conducted surveys to assess the mass sport situation in China. The surveys were conducted in the years 1997, 2001, 2007 and 2015. The built environment is an effective intervention to promote sport and physical activity among the nation. The Chinese government is also using the built environment intervention to promote sport and physical activity culture in China. The Chinese government started to construct playgrounds, green parks, walking trails and sports venues for global sports competitions. The 6th National Sports Venues Census of China was conducted to assess the status and situation of the sports venues in China.

\section{Results}

The primary data collected through the interview guide was analyzed through quantitative content analysis. The similar themes were categorized into four main themes based on the study participant's national fitness plan's knowledge.

\section{Types of Sports for Physical Activity Used to Perform by the Study Participants}

Table 2 shows the types of sports in the gender paradigm performed by the study participants for physical activity. The table statistics show that majority of the men about (27.3\%) and women about (28.6\%) participated in running and fitness walk. Chinese men about (27.3\%) also participated in traditional Chinese exercises. Chinese women about (14.3\%) used rope skipping as physical activity, and about (18.2\%) Chinese men played badminton sport for physical exercise.

\section{Time Spent on Sports and Physical Activity by the Study Participants}

Table 3 shows the time distribution spent for sports and physical activity in the gender paradigm. According to the table statistics, most of the women about (50.0\%) spent more than 30 minutes, and most of the men about (45.4\%) spent 30 minutes on sports and physical activity.

Table 2 Types of Sports for Physical Activity Used to Perform by the Study Participants $(\mathrm{N}=25)$

\begin{tabular}{|c|c|c|}
\hline \multirow{2}{*}{$\begin{array}{l}\text { Type of Sports for Physical } \\
\text { Activity }\end{array}$} & \multicolumn{2}{|c|}{ Gender } \\
\hline & $\begin{array}{c}\text { Male } \\
(N=I I)\end{array}$ & $\begin{array}{r}\text { Female } \\
(\mathrm{N}=\mid 4)\end{array}$ \\
\hline Running and fitness walk & $3(27.3 \%)$ & $4(28.6 \%)$ \\
\hline Badminton & $2(18.2 \%)$ & I (7.14\%) \\
\hline Traditional Chinese exercise & $3(27.3 \%)$ & I (7.14\%) \\
\hline Aerobics & I (9.09\%) & I (7.14\%) \\
\hline Basketball & I (9.09\%) & I (7.I4\%) \\
\hline Rope Skipping & - & $2(14.3 \%)$ \\
\hline Others & I (9.09\%) & I (7.|4\%) \\
\hline
\end{tabular}


Table 3 Time Spent on Sports and Physical Activity by the Study Participants $(\mathrm{N}=25)$

\begin{tabular}{|l|c|c|}
\hline \multirow{2}{*}{$\begin{array}{l}\text { Time Spent on Sports and } \\
\text { Physical Activity }\end{array}$} & \multicolumn{2}{|c|}{ Gender } \\
\cline { 2 - 3 } & $\begin{array}{c}\text { Male } \\
\text { (N=II) }\end{array}$ & $\begin{array}{c}\text { Female } \\
\text { (N=14) }\end{array}$ \\
\hline 30 Minutes & $5(45.4 \%)$ & $4(28.5 \%)$ \\
Less than 30 minutes & $3(27.3 \%)$ & $3(21.5 \%)$ \\
More than 30 minutes & $3(27.3 \%)$ & $7(50.0 \%)$ \\
\hline
\end{tabular}

\section{Categorization of the Role of the} National Fitness Plan in the Promotion of Exercise (Physical Activity) and Health Well-Being

Table 4 shows the categorization of the national fitness plan's role in promoting physical activity and well-being. Four main themes are sports environment and health,

Table 4 Categorization of the Role of National Fitness Plan in the Promotion of Physical Activity and Health Well-Being $(\mathrm{N}=25)$

\begin{tabular}{|c|c|}
\hline $\begin{array}{l}\text { Categories of the Role of } \\
\text { NFP }\end{array}$ & $\begin{array}{l}\text { Words and Phrases Used by the } \\
\text { Interview Participants }\end{array}$ \\
\hline $\begin{array}{l}\text { Sports Environment and } \\
\text { Health }\end{array}$ & $\begin{array}{l}\text { Built environment and sports, Health } \\
\text { benefits of sports, Physical health, } \\
\text { Reducing sedentary behavior, active } \\
\text { commuting, Basketball courts, } \\
\text { volleyball courts, swimming pools, } \\
\text { sports equipment, and promote } \\
\text { physical activity, traditional Chinese } \\
\text { sports }\end{array}$ \\
\hline $\begin{array}{l}\text { Cycling and walking } \\
\text { Environment for Physical } \\
\text { Activity }\end{array}$ & $\begin{array}{l}\text { Availability, accessibility, and } \\
\text { proximity to green spaces, parks, } \\
\text { recreational facilities, and sidewalks, } \\
\text { walkable built environment features, } \\
\text { Cycling and walking }\end{array}$ \\
\hline $\begin{array}{l}\text { Park use among the aging } \\
\text { population }\end{array}$ & $\begin{array}{l}\text { Environments, the area of green } \\
\text { space, the size of open space, and } \\
\text { entertainment facilities, accessing the } \\
\text { physical activity areas in parks by } \\
\text { walking or cycling, the aging focus on } \\
\text { health-enhancing physical activity in } \\
\text { parks }\end{array}$ \\
\hline $\begin{array}{l}\text { Health promotion and } \\
\text { prevention from NCDs }\end{array}$ & $\begin{array}{l}\text { Active living, lifestyle change, } \\
\text { numerous trails designed for walking } \\
\text { and jogging to promote healthy living, } \\
\text { gym using trend, prevention from } \\
\text { NCDs }\end{array}$ \\
\hline
\end{tabular}

cycling and walking environment for physical activity, park use among the aging population and health promotion and prevention from NCDs extracted from the study participants' information collected through face-to-face interviews.

\section{Frequency of Each Type of the Role of the National Fitness Plan in the Promotion of} Exercise and Health Well-Being $(\mathrm{N}=25)$

Table 5 shows the participant's responses to each type of role of the national fitness plan. The majority of the participants $(32.0 \%)$ said that national fitness plan is helpful in the promotion of sports environment and health, about $(28.0 \%)$ reported that NFP is helpful in the promotion of cycling and walking environment for physical activity and health promotion and prevent from noncommunicable diseases (NCDs) while only about $(12.0 \%)$ said NFP is promoting the use of park among the aging population of China.

\section{Frequency of Each Type of the Role of National Fitness Plan in the Promotion of Physical Activity and Well-Being Gender-Wise ( $\mathrm{N}=25)$}

Table 6 shows the comparative response in the gender paradigm regarding the role of national fitness plans in promoting physical exercise and well-being. The majority of the female participants $(35.8 \%)$ reported that NFP helps promote sports environment and health, while about $(27.3 \%)$ agreed with the statement. Besides, most male participants (36.4\%) said that NFP supports cycling and walking environment for physical activity, while only about $(21.4 \%)$ females agreed with that statement. The majority of the female participants $(14.3 \%)$ stated that

Table 5 Frequency of Each Type of the Role of National Fitness Plan in the Promotion of Physical Activity and Health Well-Being $(\mathrm{N}=25)$

\begin{tabular}{|l|c|}
\hline The Role of National Fitness Plan & Participants \\
\hline Sports Environment and Health & $8(32.0 \%)$ \\
\hline $\begin{array}{l}\text { Cycling and walking Environment for Physical } \\
\text { Activity }\end{array}$ & $7(28.0 \%)$ \\
\hline Park use among the aging population & $3(12.0 \%)$ \\
\hline Health promotion and prevention from NCDs & $7(28.0 \%)$ \\
\hline
\end{tabular}


Table 6 Frequency of Each Type of the Role of National Fitness Plan in the Promotion of Physical Activity and Health Well-Being Gender-Wise $(\mathrm{N}=25)$

\begin{tabular}{|l|c|c|}
\hline \multirow{2}{*}{ The Role of National Fitness Plan } & \multicolumn{2}{|c|}{ Gender } \\
\cline { 2 - 3 } & $\begin{array}{c}\text { Male } \\
\text { (N=II) }\end{array}$ & $\begin{array}{c}\text { Female } \\
\text { (N=14) }\end{array}$ \\
\hline Sports Environment and Health & $3(27.3 \%)$ & $5(35.8 \%)$ \\
\hline $\begin{array}{l}\text { Cycling and walking Environment for } \\
\text { Physical Activity }\end{array}$ & $4(36.4 \%)$ & $3(21.4 \%)$ \\
\hline Park use among aging population & $1(9.1 \%)$ & $2(14.3 \%)$ \\
\hline $\begin{array}{l}\text { Health promotion and prevent from } \\
\text { NCDs }\end{array}$ & $3(27.3 \%)$ & $4(28.6 \%)$ \\
\hline
\end{tabular}

NFP promotes park use among China's aging population, while only about $(9.1 \%)$ male participants agreed with that statement. Moreover, most female participants (28.6\%) said that NFP plays a vital role in promoting and preventing NCDs. In comparison, a slight difference about $(27.3 \%)$ males agreed with that statement.

\section{Types of Sports and Physical Activity}

Sports and physical activity are the catalysts of an active and healthy life. The Chinese nation participates in different sports and physical activities for active living after implementing various Chinese government interventions
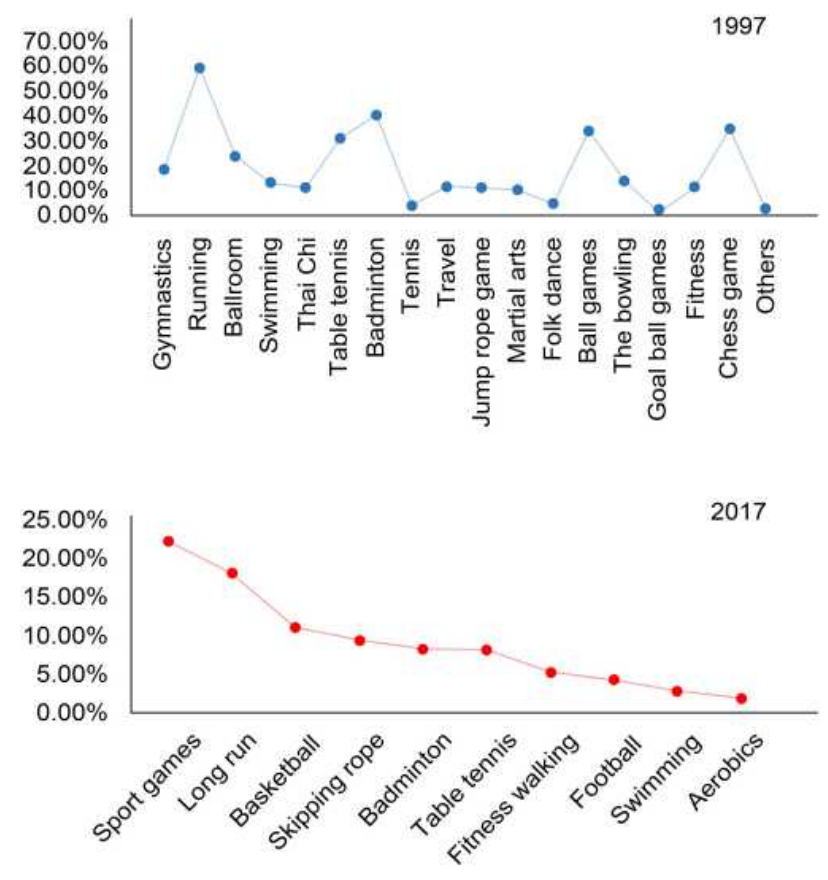

to promote sports and physical culture in Chinese society. Figure 1 shows the types of sports and physical activity which the Chinese people perform.

In 1997, most Chinese people used to participate in running as an exercise. Most people used to play badminton, table tennis, ball games, and chess games in sports. Traditional Chinese sports also have a good impact on health, and Chinese people used to participate in the Thai Chi. In 2007, most Chinese people participated in aerobic and traditional Chinese sports such as yangko, ballroom dancing, broadcast, and qigong. In 2007, sports games and the long run were the most performed activities by the Chinese people.

\section{The Trend of Sports and Physical Activity with Main Purpose}

Sports and physical activity have various benefits and improve the HRQoL. The data statistics in Figure 2 show that about (72.32\%) Chinese people participated in sports and physical activity with exercise in 1997 . Almost $(34.80 \%)$ people participated in sports to increase physical activity level in 2007, while about (35.60\%) participated in keeping fit in 2015.

\section{Sports Venues Development Under the Implementation of Various Interventions}

Sports are a vital intervention as a preventive measure against physical inactivity and NCDs. The number of

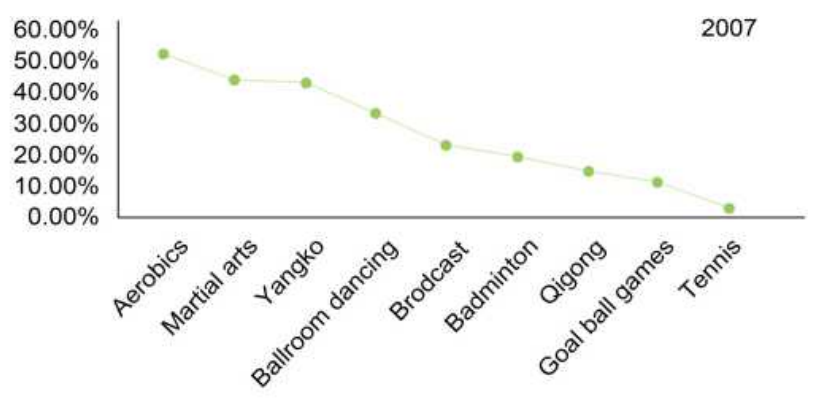

Figure I Types of sports and physical activity. 

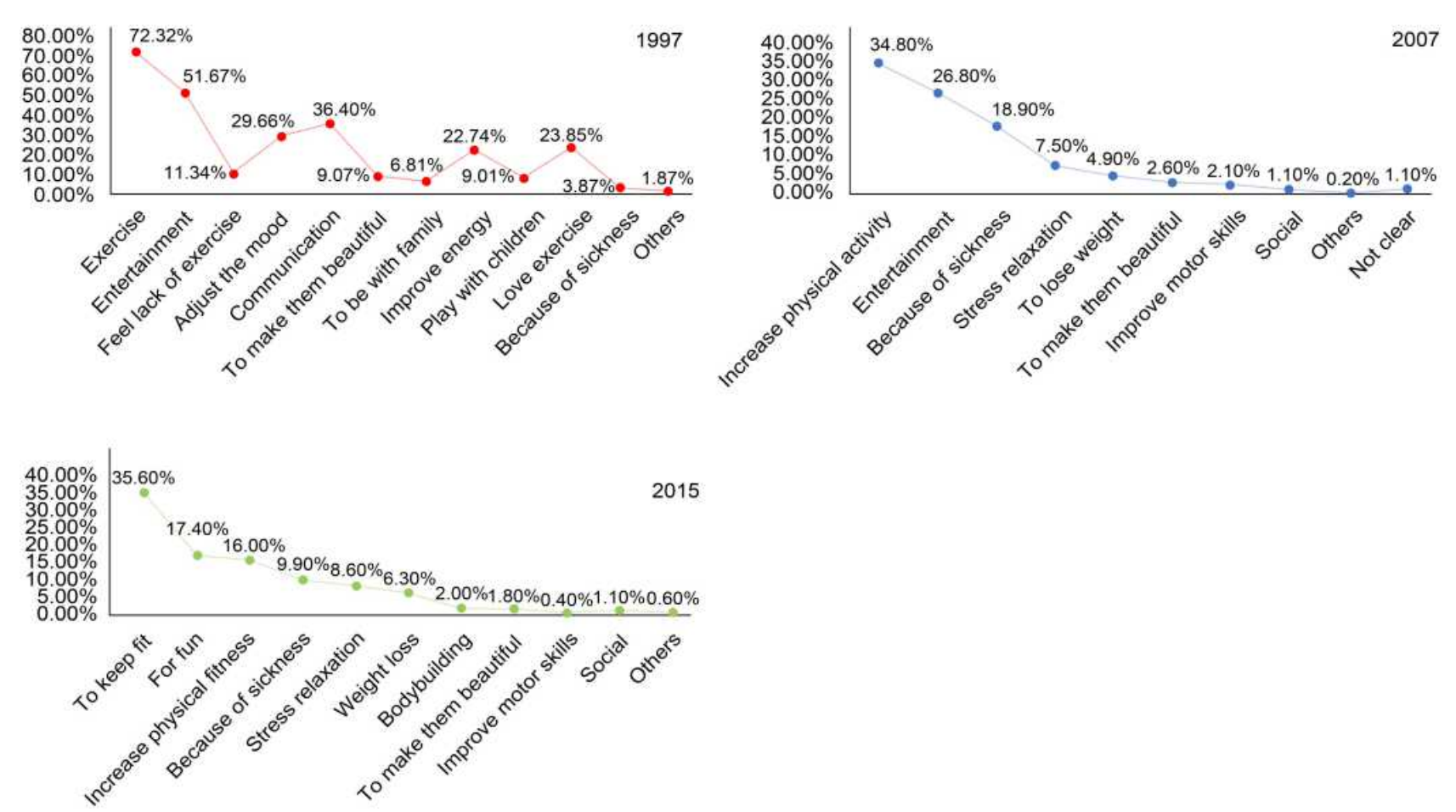

Figure 2 Trend of sports and physical activity with main purpose.

sports venues increased in China under various sports policies to promote physical culture and active living. The 6th National Sports Venues Census (NSVC) statistics of China in Figure 3 show the year-wise increased number of sports venues. According to Figure 3 statistics, sports venues increased continuously, and annual growth in terms of area and numbers rapidly observed in 2008. There were 1.69 million sports venues at the end of 2013 across China to promote sports and physical activity trends among the
Chinese nation. China's per capita area is only $0.6 \%$. The per capita area of public sports facilities in Beijing is $0.9 \mathrm{~m}^{2}$. As of the end of 2010 , there are 5750 sports venues in Beijing. There are 715 indoor venues, accounting for $12.4 \%$ of the total venues, and 5035 outdoor venues, accounting for $87.6 \%$ of the total venues. In 2001, Shanghai built 56 public sports venues, 119 fitness parks, 2664 fitness spots and various fitness clubs. More than $95 \%$ of the streets and more than $60 \%$ of the neighborhood

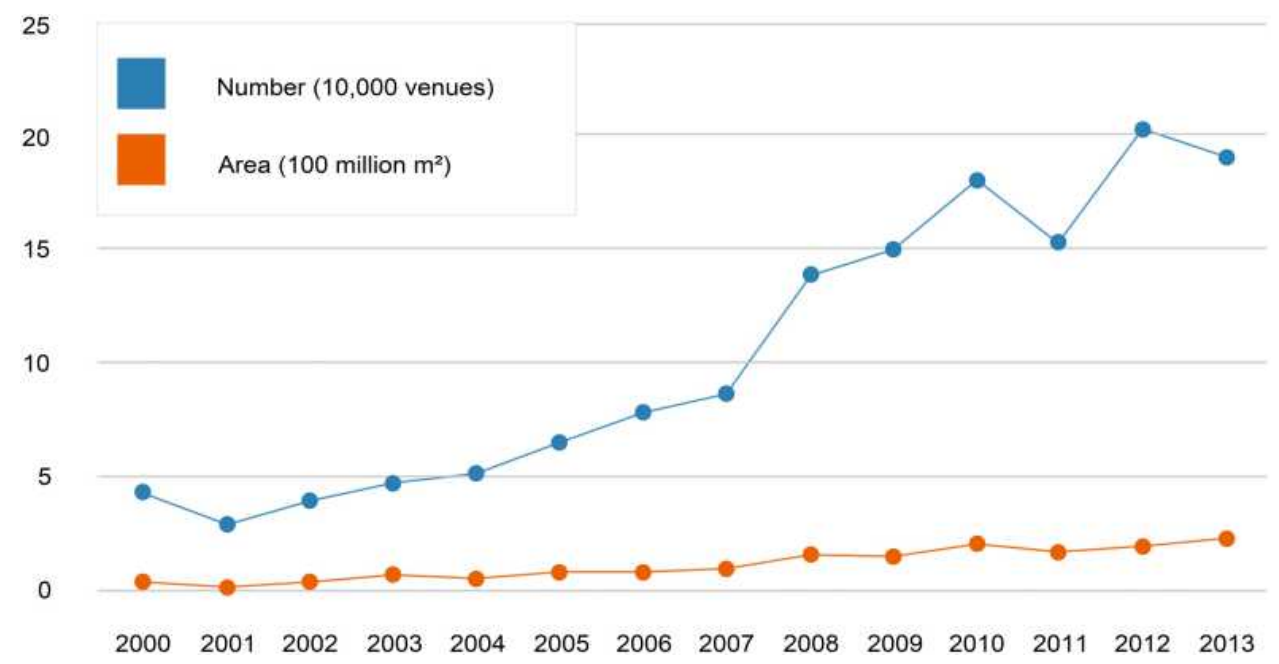

Figure 3 Sports venues development. 
committees have fitness facilities. More than $90 \%$ of the developers in Guangzhou take sports facilities as one of the key selling points of the community, and the construction of sports facilities in the commercial, residential community is essential. There are 237 sports venues in 6 communities in Wuhan. Xi'an has 48.37 sports venues per 100,000 people. Macao currently has $2937 \mathrm{~m}^{2}$ of sports venues, and the per capita sports venues have increased to $0.63 \mathrm{~m}^{2}$. According to the population of 21 million in 1999 , Taiwan has an average of 300 stadiums per 100,000 people, which has caught up with or even surpassed some developed sports countries in Europe and the United States. Taking Beijing as an example, the per capita activity area will reach $1 \mathrm{~m}^{2}$ by 2005 and $1.1 \mathrm{~m}^{2}$ by 2010 . It is necessary to build another 1.382 million $\mathrm{m}^{2}$ of rural and urban areas in Beijing to meet the needs of public fitness activities. At present, there are $13,847.3 \mathrm{~m}^{2}$ venues for every 10,000 people in the outer suburbs of Beijing. The project covers the streets, harbors, parks, squares, communities and neighborhood committees of 18 districts and counties in Beijing. ${ }^{38}$

\section{Distribution of the Formal and Informal Physical Activity and Sports Places}

Table 7 shows the distribution of the formal and informal places for physical activity and sports reported in the four time surveys of General Administration of Sport of China. ${ }^{33-36}$ In 1997, rural and urban Chinese residents used $(29.4 \%)$ formal and $(70.6 \%)$ used informal places for physical activity and sports. About (28.8\%) formal and $(71.20 \%)$ used informal places for physical activity and sports in 2001. In the year of 2007, (42.4\%) formal and $(41.2 \%)$ used informal places for sports and physical activity while about (52.6\%) formal and (49.5\%) used informal places in 2015 .

Table 7 Distribution of the Formal and Informal Physical Activity and Sports Places

\begin{tabular}{|l|c|c|}
\hline Years & Formal Places & Informal Places \\
\hline 1997 & $29.4 \%$ & $70.6 \%$ \\
2001 & $28.8 \%$ & $71.20 \%$ \\
2007 & $42.4 \%$ & $41.2 \%$ \\
2015 & $52.6 \%$ & $49.5 \%$ \\
\hline
\end{tabular}

\section{Discussion}

Traditional national sports have significant importance in promoting physical activity and health well-being at the national level. Different ethnic groups of the Chinese people developed traditional national sports such as shuttlecock, dragon dance, cuqiu, lion dance, wooden ball, rubber band skipping, pearl ball, shuttlecock, and fireworks. All the traditional national sports are included in the national fitness campaign to promote active living. ${ }^{39}$ Four main themes emerged after content analysis is discussed below.

\section{Sports Environment and Health}

In developing countries, the rise in the prevalence of sedentary lifestyles is a significant problem. The foremost reason for the prevalence of NCDs is the inactive lifestyle. Participation in physical exercise and sports is the preferred approach to prevent different diseases. ${ }^{40}$ The study results showed that most participants $(32.0 \%)$ said that the national fitness plan helps promote sports environment and health. The phenomenon of lack of physical activity has been around for the last 15 years. The Chinese government implemented a National Fitness Plan (NFP) to improve the Chinese people's health through sports and recreational activities. Active and healthy living is promoting in Chinese society through physical exercise and sports, further preventing NCDs under the NFP. It also focuses on national fitness at the local level. In this context, local government in rural and urban areas shapes the ecology by using urban planning towards a healthy lifestyle. The provincial government focuses on investment in the urban infrastructure, promoting physical activity at an individual level. In China, an industrial sports revolution has begun promoting physical exercise and sports culture across the country. Physical activity and sports participation are not up to the mark in the rural areas of China. In this context, the SGAS introduced several projects named Xue-Tan Project, Township Fitness Project, and Farmers Fitness Project to provide sports facilities to the rural population. ${ }^{41}$ The ambitious target of the NFP is to enlarge sports participation, perk up fitness, and raise awareness regarding healthy living. National Fitness Programs also concentrate on the rural areas of China. As stated earlier, about 570,000 villages across the country have access to the facilities, and only 50,000 villages remain that are not yet protected by the NFP 
initiative. Besides, by 2022 to 2030, the area reserved for sports stadiums will exceed 1.9 and 2.3 square meters, respectively. ${ }^{42,43}$

\section{Cycling and Walking Environment for Physical Activity}

Daily routine exercises such as cycling, walking, and running can prevent developing the risk factor of diabetes, heart disease, strokes, and cancer. ${ }^{44}$ Physical activity in the form of cycling and walking is active travel in people's daily lives, which has positive effects on health. Cycling and walking are considered active travel, and it is influenced by many factors such as built environment, socioeconomic characteristics, and individual's attitude. ${ }^{45}$ About (28.0\%) participants reported that NFP is helpful in the promotion of cycling and walking environment for physical activity. Those areas of China, which are newlydeveloped, have built-in well-paved sidewalks, and bicycle lines are walking-friendly, further showing the built environment's high quality. In the context of the study results, a supportive, built environment is promoting physical activity trends effectively. Policymakers and urban planners must ensure street connectivity with the recreational spaces during the design and development of the urban built environment. The cycling and walking Environment for increasing the Chinese people's physical activity level is an effective intervention under NFP. Further, it will also help achieve healthier society goals and reduce the NCDs prevalence rate among the Chinese people. ${ }^{22}$ In 1995, the Chinese government initiated physical health law across the country, and the Chinese State Council also initiated the national physical fitness program (NPFP). The survey statistics issued by the State Physical Culture Administration show that about $40 \%$ population (aged 7-70 years) participate in sports and physical activity. In comparison, about $60 \%$ go to the gymnasium for physical activity. About $33.9 \%$ Chinese population took part in regular physical activity by the end of $2005 .{ }^{46}$ The M-KFTP announced the purpose to construct fitness trails about 300 kilometers by the end of 2020 in each countylevel city of China. ${ }^{47}$

\section{Park Use Among the Aging Population}

The Chinese government introduced interventions in Chinese society to raise the physical activity level among Chinese people. In this context, built Environment intervention played an important role in improving the physical activity level. A significant increase in the physical activity level in the years (2007-14) has been reported in the National Survey on physical activity in urban and rural Chinese. Further, a study conducted on parks among China's aging population said that about $50 \%$ of park users are Chinese older adults. In contrast, in the USA, only about $15 \%$ of older adults use parks for physical activity. ${ }^{48}$ Urban parks are an important place for China's aging population because they spent time there with their peers and perform various kinds of exercise to maintain their health. Sports fields, fitness stations, and green lawns are familiar visiting places among China's aging population. ${ }^{49}$ Most Chinese older adults were pensioners who went to the park for routine exercise, Qigong, light gymnastics, and dancing every day early morning. In China's public parks, much equipment is installed for activity, and older people perform different exercises to make their lives healthy and energetic. ${ }^{50}$ Traditional Chinese physical activities have numerous health benefits and cost-free. They are easily organized at the community and neighborhood level and can play an imperative role in promoting physical exercise at the local and national levels. ${ }^{51}$ It is proved that the use of parks among older Chinese adults helps promote physical activity. As the physical activity level increases among the aging Chinese population, it would be beneficial to achieve Healthy China and sustainable development goals, essential to a healthier society.

\section{Health Promotion and Prevention from NCDs}

The biggest health threat is NCDs in China. About over $80 \%$ (10.3 million) annual deaths are happening due to NCDs. ${ }^{16}$ According to the WHO, about $68.6 \%$ of the disease burden is NCDs. ${ }^{17}$ Other NCDs' prevalence rate was higher in rural populations than the urban population, such as type 2 diabetes and hypercholesterolemia rate increased among China's rural people, about 304.2\% (from $2.4 \%$ to $9.7 \%$ ) and $366.7 \%$ (from $1.8 \%$ to $8.4 \%$ ). In urban China, it increased about $197.6 \%$ (from $4.1 \%$ to $12.2 \%$ ) and $173.3 \%$ (from $4.5 \%$ to $12.3 \%$ ). ${ }^{18}$ Diabetes mellitus (DM), cardiovascular diseases (CVDs), lung cancer, and chronic obstructive pulmonary diseases (COPDs) are the main NCDs in China. ${ }^{1}$ Most female participants (28.6\%) said that NFP plays a vital role in promoting and preventing NCDs. Similarly, according to the health map proposed by Barton and Grant that there is an association 
between the environments (social/economic/physical), the ecosystem, and health. In the ecological model, the built environment, which includes a built environment, is crucial in influencing people's well-being. ${ }^{52,53}$ Therefore, urban designs for sports under NFP is promoting physical activity trend and promoting health well-being. Moreover, its recreational features, land-use characteristics, transportation systems (public transit, streets, bike trails, and footpath for walking) help promote physical exercise and play a dynamic function in building a healthy society. The fitness walk and jogging trend among the Chinese population are significantly improved after the implementation of NFP. Nationwide about 12,229 fitness trails in China and above (95\%) provide 24 hours access for physical activity. $^{54}$

\section{Conclusion}

Physical inactivity is the leading cause of mortality globally, which has implications on the prevalence of NCDs. Environmental and societal changes have effects on the physical activity level of the population. The main drivers of the change for physical activity trend among the Chinese nation are urbanization, increased use of motorized transport, and mechanization in modern society. In the social, physical, and mental growth of men and women, physical exercise and sports are pertinent. Physical activity levels increasing among the aging Chinese population after NFP implementation, and it would help achieve a healthier Chinese society. It is proved that the use of parks among older Chinese adults has been increased after the NFP implementation, which helps promote physical activity. The designed urban environment for sports and physical exercise has a significant effect on the lives of the elderly population. Since the introduction of the NFP, the aging Chinese population has shown a notable trend in physical activity participation. Implementing the "senior playgrounds" strategy with physical fitness equipment among the aging population encourages physical activity. Besides, the active travel (walking and cycling) intervention also contributing to the promotion of physical activity among Chinese adults. Physical activity and health status have a linear relationship as physical activity increases and physical fitness and health also improved. The elimination of physical inactivity through the built environment would eradicate the major NCDs from about $6 \%$ to $10 \%$ and increase life expectancy.

\section{Abbreviations}

NFP, national fitness plan; NCDs, non-communicable diseases; WHO, world health organization; NPFP, national physical fitness program; HRQoL, health-related quality of life; NSVC, national sports venues census; M-KFTP, million-kilometer fitness trail project; SGAS, state of the general administration of sports.

\section{Ethical Approval}

The ethics committee of Soochow University, Suzhou, People's Republic of China, approved the current study's research protocol. The study participants signed consent was received during the informed consent procedure. The study complied with the Declaration of Helsinki, and it was assured that all the data were used only for research purposes.

\section{Acknowledgments}

We would like to highly thankful to all the researchers for data collection and processing. Moreover, acknowledge all the survey participants in our study.

\section{Funding}

Current article is a part of "Study on the Government Cultivation of Spontaneous Sports Organizations in China." Funded by the National Social Science Fund of China (16BTY033, 2016.8-2021.12, PI: DaiJianhui).

\section{Disclosure}

The authors report no conflicts of interest in this work.

\section{References}

1. World Health Organization. Global health risks: mortality and burden of disease attributable to selected major risks; 2009 Available from: https://apps.who.int/iris/handle/10665/44203. AccessedMay 28, 2021.

2. Lee I-M, Shiroma EJ, Lobelo F, Puska P, Blair SN, Katzmarzyk PT. Effect of physical inactivity on major non-communicable diseases worldwide: an analysis of burden of disease and life expectancy. Lancet. 2012;380(9838):219-229. doi:10.1016/s0140-6736(12) 61031-9

3. World Health Organization. Physical Activity [Internet]. Available from: https://www.who.int/news-room/fact-sheets/detail/physicalactivity. Accessed November 18, 2020.

4. Lees SJ, Booth FW. Sedentary Death Syndrome. Can J Appl Physciol. 2004;29(4):447-460. doi:10.1139/h04-029

5. Mokdad AH. Actual causes of death in the United States, 2000. JAMA. 2004;291(10):1238. doi:10.1001/jama.291.10.1238

6. Zhou S, Davison K, Qin F, Lin K-F, Chow B-C, Zhao J-X. The roles of exercise professionals in the health care system: a comparison between Australia and China. J Exerc Sci Fit. 2019;17(3):81-90. doi:10.1016/j.jesf.2019.04.001 
7. Chai W, Nigg CR, Pagano IS, Motl RW, Horwath C, Dishman RK. Associations of quality of life with physical activity, fruit and vegetable consumption, and physical inactivity in a free living, multiethnic population in Hawaii: a longitudinal study. Int $J$ Behav Nutr Phys Act. 2010;7(1):83. doi:10.1186/1479-5868-7-83

8. Florindo AA, Guimarães VV, Cesar CL, de Azevedo Barros MB, Alves MC, Goldbaum M. Epidemiology of leisure, transportation, occupational, and household physical activity: prevalence and associated factors. J Phys Act Health. 2009;6(5):625-632. doi:10.1123/ jpah.6.5.625

9. Ng SW, Norton EC, Popkin BM. Why have physical activity levels declined among Chinese adults? Findings from the 1991-2006 China health and nutrition surveys. Soc Sci Med. 2009;68(7):1305-1314. doi:10.1016/j.socscimed.2009.01.035

10. Zhang X, Song Y, Yang TB, Zhang B, Dong B, Ma J. Analysis of current situation of physical activity and influencing factors in Chinese primary and middle school students in 2010. Zhonghua $Y u$ Fang Yi Xue Za Zhi. 2012;46(9):781. doi:10.3760/cma.j.issn.02539624.2012.09.003

11. Wagner A, Simon C, Evans A, et al. Physical activity patterns in 50-59 year men in France and Northern Ireland. Associations with socio-economic status and health behaviour. Eur $J$ Epidemiol. 2002;18(4):321-329. doi:10.1023/a:1023625110856

12. Hallal PC, Andersen LB, Bull FC, Guthold R, Haskell W, Ekelund U. Global physical activity levels: surveillance progress, pitfalls, and prospects. Lancet. 2012;380(9838):247-257. doi:10.1016/s01406736(12)60646-1

13. Ng SW, Popkin BM. Time use and physical activity: a shift away from movement across the globe. Obes Rev. 2012;13(8):659-680. doi: $10.1111 /$ j. $1467-789 x .2011 .00982 . x$

14. The World Bank. Toward a healthy and harmonious life in China: stemming the rising tide of non-communicable diseases; 2011. Available from: https://www.worldbank.org/content/dam/Worldbank/ document/NCD_report_en.pdf. Accessed November 20, 2020.

15. Wu F, Narimatsu H, Li X, et al. Non-communicable diseases control in China and Japan. Global Health. 2017;13(1). doi:10.1186/s12992017-0315-8

16. Chen P, Li F, Harmer P. Healthy China 2030: moving from blueprint to action with a new focus on public health. Lancet Public Health. 2019;4(9):e447. doi:10.1016/S2468-2667(19)30160-4

17. Wang L, Kong L, Wu F, Bai Y, Burton R. Preventing chronic diseases in China. Llancet. 2005;366(9499):1821-1824. doi:10.1016/S01406736(05)67344-8

18. Zhao W, Junshi C. The Exercise is Medicine (EIM) in China; 2017. Available from: https://docplayer.net/125488400-The-exercise-ismedicine-eim-in-china.html. Accessed November 11, 2020.

19. Chang JL, Wang Y. Comprehensive Report on Chinese Residents' Nutrition and Health in 2010-2013. China: Peking University Medical Press; 2016:96-116.

20. Zhou Y, Jiang W, Chan KS. A comprehensive literature reviews on national fitness policy and individual factors for physical exercise in China. OAJBS. 2020;3(2):ID.000236. doi:10.38125/OAJBS.000236

21. Helen M China unveils The new National Fitness Plan; 2016. Available from: https://america.cgtn.com/2016/06/28/china-unveilsnew-national-fitness-plan. Accessed October 11, 2020.

22. Dai J, Menhas R. Sustainable development goals, sports and physical activity: the localization of health-related sustainable development goals through sports in china: a narrative Review. Risk Manag Healthc Policy. 2020;13:1419-1430. doi:10.2147/rmhp.s257844

23. Fen YS, Hong LK. Exercise as a healthy lifestyle choice: a review and avenues for future research. Int Bus Res. 2009;2(1):146-158. doi:10.5539/ibr.v2n1p146

24. Barringer BR, Jones FF, Neubaum DO. A quantitative content analysis of the characteristics of rapid-growth firms and their founders. J Bus Ventur. 2005;20(5):663-687. doi:10.1016/j. jbusvent.2004.03.004
25. Schoonenboom J, Johnson RB. How to construct a mixed methods research design. Kolner Z Soz Sozpsychol. 2017;69(Supp1 2):107-131. doi:10.1007/s11577-017-0454-1

26. Scheufele B. Content analysis, quantitative. Intl Ency Commun. 2008. doi:10.1002/9781405186407.wbiecc135

27. Downe-Wamboldt B. Content analysis: method, applications, and issues. Health Care Women Int. 1992;13(3):313-321. doi:10.1080/ 07399339209516006

28. Mikkonen K, Kyngäs H. Content Analysis in Mixed Methods Research. In: The Application of Content Analysis in Nursing Science Research. 2019;31-40. doi:10.1007/978-3-030-30199-6_4

29. Manganello J, Blake N. A study of quantitative content analysis of health messages in US Media From 1985 to 2005. Health Commun. 2010;25(5):387-396. doi:10.1080/10410236.2010.483333

30. Kolbe RH, Burnett MS. Content-analysis research: an examination of applications with directives for improving research reliability and objectivity. J Consum Res. 1991;18(2):243. doi:10.1086/209256

31. Patton MQ. Qualitative Research and Evaluation Methods. 4th ed. Los Angeles: Sage; 2015.

32. McGrath C, Palmgren PJ, Liljedahl M. Twelve tips for conducting qualitative research interviews. Med Teach. 2018;41(9):1002-1006. doi:10.1080/0142159X.2018.1497149

33. General administration of sports of China Survey; 1997. Available from: https://xueshu.baidu.com/usercenter/paper/show?paperid= 8e2b64ed4609255d5d5021fefddc92d5\&site=xueshu_se. Accessed February 14, 2021.

34. General administration of sports of China Survey; 2001. Available from: http://www.sport.gov.cn/n16/n1077/n1422/7300210.html. Accessed February 14, 2021.

35. General administration of sports of China Survey; 2007. Available from: http://www.sport.gov.cn/n16/n1077/n1422/7300210.html. Accessed February 14, 2021.

36. General administration of sports of China survey; 2015. Available from: http://www.sport.gov.cn/n16/n1077/n1422/7300210.html. Accessed February 14, 2021.

37. Department of Sports Economy, General Administration of Sport of China. The data compilation of the sixth national sports venues census. Available from: http://www.sport.gov.cn/pucha/index.html. Accessed February 12, 2021.

38. Huirong X. Changes in Sports Consumption of Urban Residents. Education press; 2001:266.

39. Li Y, Wang H, Deng M. Exploitation of national fitness project in physical education in Middle School. Adv Phys Educ. 2017;07 (04):409-417. doi:10.4236/ape.2017.74034

40. Li X, Song J, Lin T, Dixon J, Zhang G, Ye H. Urbanization and health in China, thinking at the national, local, and individual levels. Environ Health. 2016;15(S1):S1. doi:10.1186/s12940-0160104-5

41. Chen Q, Liu T. The effectiveness of community sports provision on social inclusion and public health in rural China. Int $J$ Environ Res Public Health. 2020;17(2):597. doi:10.3390/ijerph17020597

42. Wang C. The investigation of the Changchun City National Fitness Path. J Jilin Architect Civil Eng. 2013;30:111-114.

43. China to increase rural access to sports facilities [Internet]. Available from: http://www.chinadaily.com.cn/a/201907/20/ WS5d31f0eea310d83056400027.html. Accessed November 19, 2020.

44. South China Morning Post. Cycling and walking a good thing - even in polluted cities; 2016. Available from: https://www.scmp.com/life style/health/article/1941634/cycling-and-walking-good-thing-evenpolluted-cities. Accessed March 2, 2021.

45. Feng J. The built environment and active travel: evidence from Nanjing, China. Int J Environ Res Public Health. 2016;13(3):301. doi:10.3390/ijerph13030301

46. Nationwide Physical Fitness Program. Available from: http://www. china.org.cn/english/features/Brief/191545.htm. Accessed March 2, 2021. 
47. Multi-department Notice on Issuing the Implementation plan for the million-kilometer walking trail project. Available from: http://www. gov.cn/xinwen/201803/16/content_5274663.htm. Accessed December 2, 2020.

48. Traverso $\mathrm{V}$ The cities designing playgrounds for the elderly. BBC Work life, 2019. Available from:https://www.bbc.com/worklife/arti cle/20191028-the-cities-designing-playgrounds-for-the-elderly. Accessed January 11, 2021.

49. Duan Y, Wagner P, Zhang R, Wulff H, Brehm W. Physical activity areas in urban parks and their use by the elderly from two cities in China and Germany. Landsc Urban Plan. 2018;178:261-269. doi:10.1016/j.landurbplan.2018.06.009

50. Muntner P, Gu D, Wildman RP, et al. Prevalence of physical activity among chinese adults: results from the international collaborative study of cardiovascular disease in Asia. Am J Public Health. 2005;95(9):1631-1636. doi:10.2105/AJPH.2004.044743
51. Guo Y, Shi H, Yu D, Qiu P. Health benefits of traditional Chinese sports and physical activity for older adults: a systematic review of evidence. J Sport Health Sci. 2016;5(3):270-280. doi:10.1016/j. jshs.2016.07.002

52. Barton H, Grant M. Urban Planning for Healthy Cities. J Urban Health. 2012;90(S1):129-141. doi:10.1007/s11524-011-9649-3

53. Barton H, Grant M. A health map for the local human habitat. $J \quad R$ Soc Promot Health. 2006;126(6):252-253. doi:10.1177/ 1466424006070466

54. Wang K, Wang X. Providing Sports Venues on Mainland China: implications for promoting leisure-time physical activity and national fitness policies. Int J Environ Res Public Health. 2020;17(14):5136. doi:10.3390/ijerph17145136
Risk Management and Healthcare Policy

\section{Publish your work in this journal}

Risk Management and Healthcare Policy is an international, peerreviewed, open access journal focusing on all aspects of public health, policy, and preventative measures to promote good health and improve morbidity and mortality in the population. The journal welcomes submitted papers covering original research, basic science, clinical \& epidemiological studies, reviews and evaluations,

\section{Dovepress}

guidelines, expert opinion and commentary, case reports and extended reports. The manuscript management system is completely online and includes a very quick and fair peer-review system, which is all easy to use. Visit http://www.dovepress.com/testimonials.php to read real quotes from published authors. 